\title{
Informing Leadership Education by Connecting Curricular Experiences and Leadership Outcomes
}

\author{
Aaron J. McKim \\ Assistant Professor, Michigan State University \\ East Lansing, MI 48824 \\ Jonathan J. Velez \\ Associate Professor, Oregon State University \\ Corvallis, OR 97331
}

\begin{abstract}
Linking specific learning experiences to leadership development has the potential to enhance leadership education. In this study, we sought to link student growth in 13 leadership areas to specific learning experiences within a leadership development program. We measured development within the 13 areas by comparing the perceived needs of students before and after engagement in the program. Evidence of connections between leadership development and specific learning experiences emerged as program facilitators documented the leadership areas addressed within the learning experiences utilized in this program. Evidence indicated students experienced the strongest growth in understanding leadership, commitment to serving, enhancing communication, ethical behavior, and valuing diversity. These areas of growth were linked to specific learning experiences, including program seminars, book readings, working with a mentor, and participation in a community organization. While this research is only an initial step in definitively linking specific learning experiences with leadership development, the results provide leadership educators with important considerations to enhance their practice. Additionally, this research provides a viable method for linking learning experiences and leadership skill development that, if replicated, could support the continued, positive impact of leadership education.
\end{abstract}

\section{Introduction \& Conceptual Framework}

Leadership skills are critical for success in today's professional culture (APLU, 2009; Day, 2001; McCall, 1998; NACE, 2014; Vicere \& Fulmer, 1998). Therefore, many organizations are actively seeking employees with a developed leadership skill set (APLU, 2009). The higher education experience has been identified as an optimal time to develop these coveted leadership skills (Astin \& Astin, 2000). Additionally, the leadership research agenda recommended identifying effective methods for developing leadership at the post-secondary level as a research priority (Andenoro et al., 2013). Therefore, the goal of our research was to identify effective methods for leadership development by linking measurable leadership skill growth and specific curricular approaches used in a year long, post-secondary leadership development program. 
In order to identify effective methods for developing leadership skills, researchers must connect curricular experiences and leadership skill development. Aligning experiences with leadership skills has been a gap identified by a variety of researchers in the leadership education literature (Allen \& Hartman, 2009; Day, 2001; Goertzen, 2009; Jenkins, 2012; Morgan, King, \& Rudd, 2013). In order to begin to bridge the gap between pedagogy and skill development, we must build our understanding of both concepts.

A number of researchers have studied pedagogical techniques used in leadership classrooms (Albert \& Vadla, 2009; Allen \& Hartman, 2009; Conger, 1992; Day, 2001; Eich, 2008; Jenkins, 2012; Zimmerman-Oster \& Burkhardt, 1999). Synthesis of this literature reveals a number of consistent strategies used to engage students in leadership development; we will describe four of these consistent strategies. The first, experiential learning (Allen \& Hartman, 2009; Day, 2001; Eich, 2008), refers to the process of engaging in an activity, reflecting on your engagement, developing new ideas, and implementing those new ideas (Kolb, 1984). The second pedagogical strategy, the use of self-assessments (Allen \& Hartman, 2009; Day, 2001; Zimmerman-Oster \& Burkhardt, 2009), seeks to develop self-awareness of strengths and weaknesses among leadership learners (Allen \& Hartman, 2009). Placing students with mentors has also been identified as a commonly used strategy in leadership development programs (Allen \& Hartman, 2009; Day, 2001; Zimmerman-Oster \& Burkhardt, 2009). Being mentored offers students an opportunity to gather feedback from someone who often has more leadership experience. The final consistent strategy, reflection (Allen \& Hartman, 2009; Jenkins, 2012; Zimmerman-Oster \& Burkhardt, 2009), offers students an opportunity to review their experiences and learn from their own involvement (Allen \& Hartman, 2009).

The pedagogical approaches used in leadership education have been categorized into four areas: (a) personal growth, (b) conceptual understanding, (c) feedback, and (d) skill building (Conger, 1992). Personal growth, as an approach to leadership development, was built on the idea that leaders are those individuals who "are deeply in touch with their personal dreams and talents and who will act to fulfill them" (Conger, 1992, pp. 45-46). Furthermore, it can be asserted that, in order to commit to the development and progress of others, you must first commit to your own personal development and progress. Conger identified the second approach to leadership development, conceptual understanding, as the intake of new information pertaining to leadership; including but not limited to, learning new leadership theories and models. Feedback, the third approach identified by Conger, is the process in which an individual learns their strengths and weaknesses as a leader. It can be reasoned that a leader aware of his or her own strengths and weakness will be more confident in their role as a leader and more prepared to continue their development as a leader. The fourth approach to leadership development is skill building, a necessary component to any complete leadership development program. Skill building refers to the process in which individuals develop specific skills to be used in different leadership contexts (Conger, 1992).

In addition to the development of leadership skills, the assessment of leadership skills is a critical component to the continual development of leadership education as a discipline (Brungardt \& Crawford, 1996). A variety of research studies have addressed the concept of leadership skill assessment (Blackwell, Cummins, Townsend, \& Cummings, 2007; Brungardt \& Crawford, 1996; Goertzen, 2009; Rosch \& Caza, 2012; Rosch \& Schwartz, 2009; Williams, 
Townsend, \& Linder, 2005). Some studies have focused on the methods of assessing leadership skills (Goertzen, 2009; Rosch \& Schwartz, 2009) while others have focused on the assessment of leadership programs (Blackwell et al., 2007; Rosch \& Caza, 2012; Williams et al., 2005).

Previous assessments of programmatic effectiveness have identified a number of successful outcomes among leadership education students (Blackwell et al., 2007; Rosch \& Caza, 2012; Williams et al., 2005). Examples of these positive outcomes include: increased leadership capacity (Rosch \& Caza, 2012), leadership skill development (Blackwell et al., 2007), and self-perceived leadership knowledge (Williams et al., 2005). These studies provide evidence that leadership programs at the college level can be an effective tool in the development of leadership skills; however, they fail to illuminate specific pedagogical approaches linked to these leadership outcomes.

One potential method for the assessment of leadership skills with little exploration in the leadership discipline is the needs assessment model (Borich, 1980). This model identifies individuals' perceived needs by measuring the discrepancy between perceived importance and perceived competence of a specified skill (Borich, 1980). Use of this method in the leadership development discipline has the potential to improve leadership program administrators' ability to identify needs among learners engaged in a program as well as to assess the development of leadership skills by measuring the change in perceived needs. In this study, we utilized the needs assessment approach to analyze leadership skill development among postsecondary students.

The theoretical foundation for our analysis was the input, environment, and outcomes model described within the theory of student involvement (Astin, 1999). This model posits students enter an educational program with specific attributes (i.e. inputs) and through an experience they are changed (i.e. outcomes). We operationalized this model within our analysis using the following process, students' perceived leadership needs were assessed before engaging in the leadership development program (i.e. inputs), their leadership needs were again assessed after their experience (i.e. outcomes). A decrease in perceived leadership needs was operationalized as leadership skill development and was then linked to specific curricular experiences. Figure 1 illustrates the operational framework used in our analysis. 


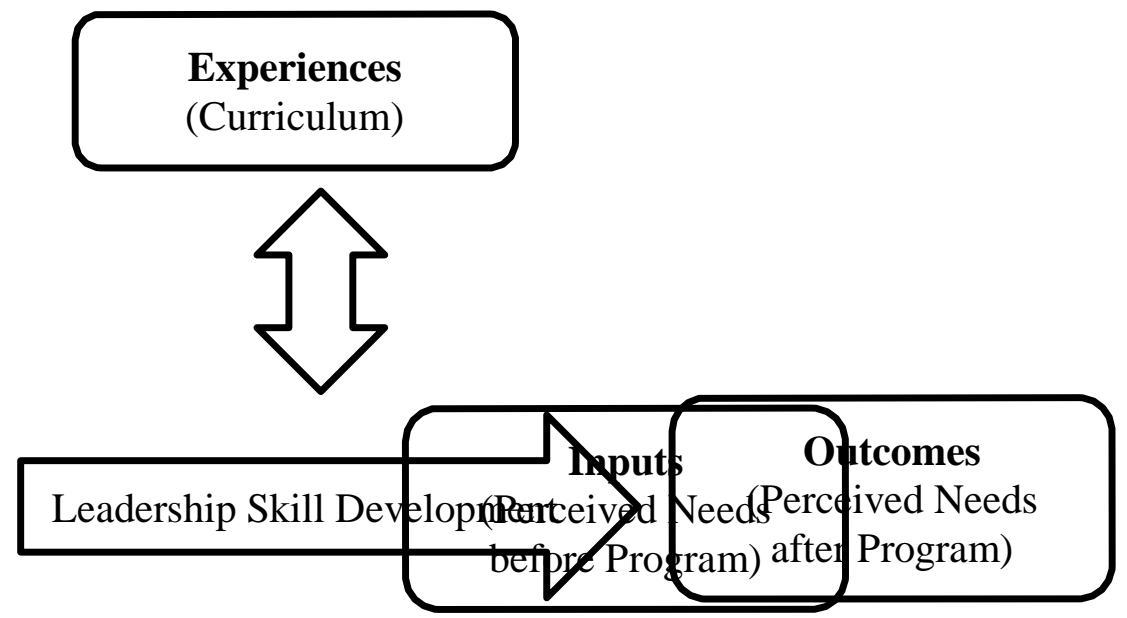

Figure 1. Operational framework for the relationship between curriculum and leadership skill development.

\section{Research Purpose \& Questions}

The purpose of this research was to (a) measure leadership skill development through a year-long leadership development program, and (b) provide potential links between leadership skill development and curricula utilized during a leadership development program. By completing this study, researchers sought to evaluate the effectiveness of certain leadership development experiences. This line of inquiry is supported by the Association of Leadership Educators Research Agenda Priority Area 1: Teaching, Learning, and Curriculum Development, which recommends the exploration of curriculum development frameworks to enhance the leadership education transfer of learning (Andenoro et al., 2013). The development and execution of this research project was guided by the following research questions.

1. What are the perceived leadership needs of students when they enter the leadership development program?

2. What are the perceived leadership needs of students when they complete the leadership development program?

3. How do the perceived leadership needs of students change during the leadership development program?

4. What experiences did students participate in, through the leadership development program, which focused on developing their specific leadership needs?

\section{Research Methods}

The population for this research were two cohorts $(N=23)$ of students enrolled in a yearlong leadership development program at a large northwest university. The leadership development program was housed in the College of Agricultural Sciences and was available to students enrolled in the College of Agricultural Sciences, College of Forestry, and College of Earth, Ocean and Atmospheric Sciences. Students enrolled in the program ranged from 
sophomore to senior standing. Students completed an application and interview and were selected based on their potential for leadership development. The program consisted of three major components: (a) a two hour, weekly, structured class meeting, (b) students paired with a faculty mentor, and (c) community and on-campus leadership experiences. The program curriculum was sequenced and separated into three sections with a progression from personal leadership to creating change to giving back and leaving a legacy. Primarily a co-curricular program, students participating in the leadership development program were asked to enroll for one credit per quarter.

Leadership needs and skill development were assessed using the leadership needs assessment (LNA; Velez, McKim, \& Simonsen, 2013). This 88 question instrument measured perceived importance and perceived competence scaled from 1 (Not at all Important/Competent) to 6 (Extremely Important/Competent). The 88 questions were concatenated into 13 leadership constructs. The constructs include understands leadership, awareness of self, practices ethical behavior, sustains leadership, values diversity, enhances communication skills, manages conflict, develops teams, leads change, manages projects, practices citizenship, understands community complexity, and committed to serving others. In each of the 13 areas of leadership, a mean weighted discrepancy score (MWDS) was calculated. MWDSs were calculated by determining the discrepancy between the perceived importance and competence of each item in the construct; that discrepancy was then multiplied by the importance mean and divided by the number of observations (see formula below; Borich, 1980).

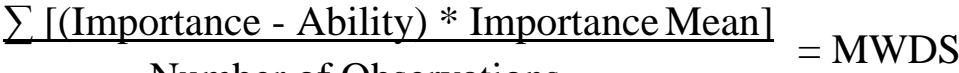 \\ Number of Observations}

The 13 leadership areas were ranked based on MWDS, with larger MWDS indicating a higher level of need. A pilot test of the instrument revealed reliabilities, using Cronbach's alphas, ranging from $\alpha=.89$ to $\alpha=.96$.

The first round of data collection was administered prior to student engagement in the leadership development program (i.e. Fall 2012 and Fall 2013). The final assessment of leadership needs was administered one week after the completion of the leadership development program (i.e. Spring 2013 and Spring 2014). All students in the population of interest $(N=23)$ completed both the pre and post assessment. On average, students took approximately 15 minutes to complete the assessment. Data for both the pre and post assessment were collected by researchers and analyzed using the Statistical Package for the Social Sciences (SPSS). In addition to the needs assessment, researchers administered a survey to the three faculty members involved in the program. Faculty members were asked to identify, for each of the seminars and experiences in the program, the two leadership need areas that were met by the objectives of that experience. These data were utilized to answer research objective number four "What experiences did students participate in, through the leadership development program, focused on developing specific leadership needs?"

The leadership research pitfalls identified by Rosch and Schwartz (2009) were evaluated as a method to enhance the quality of this research. The honeymoon effect (i.e. participants 
exaggerating the effects of a program right after its completion) was addressed by allowing a one-week gap between program completion and the final assessment of leadership needs. The horizon effect (i.e. participants not adequately knowing their skills in a given area until they have gone through sufficient training in that area) was weakened by the majority of students involved in the program having adequate leadership experiences prior to the first assessment. Those previous experiences may have led students to a better understanding of their leadership skills prior to assessment. The Hollywood effect (i.e. participants ranking themselves strong in areas they feel they need to be strong in to be a leader) was potentially weakened by the needs assessment addressing the importance as well as competence in each skill; therefore, if students felt the skill was important they could address that separate from their competence. The halo effect (i.e. the thought that outside observers feel that if an individual is good at one skill they are good at all skills) was addressed by using a self-assessment and students having adequate leadership experiences to understand the different concepts addressed by the instrument. Finally, the hallmark effect (i.e. individuals with little self-confidence will often score themselves lower in many areas) was potentially weakened by the motivation and self-confidence required for students to apply for a year-long leadership development program. We acknowledge our methodology does not eliminate all the potential pitfalls for leadership research; however, we feel the unique methodology employed through the LNA may offer some advantages as we strive for high quality leadership education research.

\section{Findings}

In order to answer research question one, "what are the perceived leadership needs of students when they enter the leadership development program?" MWDSs were calculated for each of the 13 constructs, first for each individual and then an average for the participants (see Table 1). The MWDSs were ranked from one to 13, with a higher MWDS indicating a higher perceived need; therefore, the leadership areas with the lower rank indicate a higher perceived need among the cohort of leadership development students.

Overall, students felt the 13 leadership skills were important. Students perceived ethical behavior $(\mu=5.63)$, sustaining leadership $(\mu=5.43)$, and developing teams $(\mu=5.40)$ as the most important leadership areas assessed. Alternatively, students perceived understanding leadership $(\mu=5.06)$, understanding community $(\mu=5.07)$, and practicing citizenship ( $\mu=$ 5.07) as the least important leadership skills evaluated in this assessment. Students perceived a higher level of importance than competence in each of the 13 leadership skill areas. The highest level of competence before the leadership development program was perceived in the areas of ethical behavior $(\mu=4.77)$, developing teams $(\mu=4.42)$, and valuing diversity $(\mu=4.41)$. The areas of lowest perceived competence were in commitment to serving $(\mu=3.75)$, understanding community $(\mu=3.85)$, and practicing citizenship $(\mu=3.88)$. 
Table 1.

Perceived Importance, Competence, MWDS, and Rank of the 13 Leadership Areas Perceived by Students before Engagement in the Leadership Development Program

\begin{tabular}{lcccc}
\hline Leadership Area & $\begin{array}{c}\text { Perceived } \\
\text { Importance }^{1}\end{array}$ & $\begin{array}{c}\text { Perceived } \\
\text { Competence }^{2}\end{array}$ & MWDS $^{3}$ & Rank \\
\hline Awareness of Self & 5.27 & 4.30 & 5.14 & 12 \\
Commitment to Serving & 5.17 & 3.75 & 7.36 & 1 \\
Developing Teams & 5.40 & 4.42 & 5.27 & 10 \\
Enhancing Communication & 5.27 & 4.09 & 6.22 & 2 \\
Ethical Behavior & 5.63 & 4.77 & 4.85 & 13 \\
Leading Change & 5.19 & 4.12 & 5.54 & 9 \\
Managing Conflict & 5.13 & 3.94 & 6.11 & 4 \\
Managing Projects & 5.35 & 4.25 & 5.88 & 6 \\
Practicing Citizenship & 5.07 & 3.88 & 6.05 & 5 \\
Sustaining Leadership & 5.43 & 4.40 & 5.61 & 7 \\
Understanding Community & 5.07 & 3.85 & 6.15 & 3 \\
Understanding Leadership & 5.06 & 3.96 & 5.54 & 8 \\
Valuing Diversity & 5.38 & 4.41 & 5.20 & 11 \\
\hline
\end{tabular}

${ }^{1}$ Items scaled from 1 (Not at all Important) to 6 (Extremely Important)

${ }^{2}$ Items scaled from 1 (Not at all Competent) to 6 (Extremely Competent)

${ }^{3}$ Mean Weighted Discrepancy Score, higher score indicates a higher perceived need.

The MWDS scores (see Table 1) indicate students perceived the largest need in the areas of commitment to serving (MWDS $=7.36$ ), enhancing communication (MWDS $=6.22$ ), and understanding community (MWDS $=6.15$ ). A higher MWDS suggests students valued that attribute of leadership as important, but felt relatively low in their competence toward this leadership component. Alternatively, a smaller MWDS identifies areas in which the gap between perceived importance and competence was smaller. The areas of lowest perceived need, measured before involvement in the leadership development program, were ethical behavior (MWDS = 4.85), awareness of self (MWDS = 5.14), and valuing diversity (MWDS = 5.20).

Students completed the leadership needs assessment again, a week after finishing the program. These results were used to answer research question number two, "what are the 
perceived leadership needs of students when they complete the leadership development program?" Importance and competence scores were calculated for each student and then combined to develop an average importance and competence for each of the 13 leadership areas. Likewise, MWDSs were calculated first for each student and then an average MWDS was calculated for the sample of students (see Table 2).

Table 2.

Perceived Importance, Competence, MWDS and Rank of 13 Leadership Areas Perceived by Students after Engagement in the Leadership Development Program

\begin{tabular}{|c|c|c|c|c|}
\hline Leadership Area & $\begin{array}{c}\text { Perceived } \\
\text { Importance }^{1}\end{array}$ & $\begin{array}{c}\text { Perceived } \\
\text { Competence }^{2}\end{array}$ & $\mathrm{MWDS}^{3}$ & Rank \\
\hline Awareness of Self & 5.32 & 4.63 & 3.67 & 9 \\
\hline Commitment to Serving & 5.17 & 4.16 & 5.25 & 3 \\
\hline Developing Teams & 5.36 & 4.68 & 3.66 & 10 \\
\hline Enhancing Communication & 5.38 & 4.59 & 4.25 & 5 \\
\hline Ethical Behavior & 5.61 & 5.09 & 2.90 & 13 \\
\hline Leading Change & 5.19 & 4.43 & 3.98 & 7 \\
\hline Managing Conflict & 5.30 & 4.22 & 5.76 & 1 \\
\hline Managing Projects & 5.35 & 4.56 & 4.20 & 6 \\
\hline Practicing Citizenship & 5.15 & 4.30 & 4.36 & 4 \\
\hline Sustaining Leadership & 5.54 & 4.84 & 3.88 & 8 \\
\hline Understanding Community & 5.11 & 4.07 & 5.34 & 2 \\
\hline Understanding Leadership & 5.31 & 4.70 & 3.28 & 12 \\
\hline Valuing Diversity & 5.49 & 4.86 & 3.43 & 11 \\
\hline
\end{tabular}

After completion of the program, the leadership areas perceived as the mostimportant were ethical behavior $(\mu=5.61)$, sustaining leadership $(\mu=5.54)$, and valuing diversity $(\mu=$ 5.49). The areas perceived as the least important were understanding community $(\mu=5.11)$, practicing citizenship $(\mu=5.15)$, and commitment to serving $(\mu=5.17)$. 
After completion of the leadership development program, students' perception of their competence in the 13 areas of leadership remained lower than their perception of the importance for each of the areas assessed. After completing the program, students perceived the most competence in ethical behavior $(\mu=5.09)$, valuing diversity $(\mu=4.86)$, and sustaining leadership $(\mu=4.84)$. Alternatively, students perceived the least amount of competence in understanding community $(\mu=4.07)$, commitment to serving $(\mu=4.16)$, and managing conflict $(\mu=4.22)$.

The MWDS scores, after the completion of the program, indicate students perceived the highest need in the areas of managing conflict (MWDS $=5.76$ ), understanding community (MWDS = 5.34), and commitment to serving (MWDS = 5.25). Alternatively, students perceived the lowest amount of need in ethical behavior (MWDS $=2.90$ ), understanding leadership (MWDS $=3.28)$, and valuing diversity $(\mathrm{MWDS}=3.43$ ).

Pre and post experience MWDSs were compared using a paired sample $t$-test to answer research question number three, "how do the perceived leadership needs of students change during a leadership development program?" A decrease in the MWDS indicates students perceived less need in that leadership area at the completion of the program than they didbefore the start of the program. Researchers suggest a decrease in the perceived need of a leadership area indicates successful development of that leadership skill. Due to the limited number of respondents, an effect size (Cohen's $d$ ) is reported to present a more realistic interpretation of the data when compared to $p$-values, which are limited when dealing with small populations and/or samples. The criteria used to describe the effect sizes are small effect $=.20$ to .49 ; medium effect $=.50$ to .79 ; and large effect $=.80$ and up (Cohen, 1988).

Students' perception of their needs in each of the 13 leadership areas decreased (see Table 3). The most substantial effect was observed in the area of enhancing communication (Cohen's $d=0.96$ ). Large effects were also seen in understanding leadership (Cohen's $d=0.86$ ) and ethical behavior (Cohen's $d=0.80$ ). Medium effects (Cohen, 1988) were observed in the areas of managing projects (Cohen's $d=0.58$ ), commitment to serving (Cohen's $d=0.56$ ), and developing teams (Cohen's $d=0.52$ ). Small effect sizes (Cohen, 1988) were identified in the areas of valuing diversity (Cohen's $d=0.49$ ), awareness of self (Cohen's $d=0.47$ ), sustaining leadership (Cohen's $d=0.43$ ), leading change (Cohen's $d=0.41$ ), practicing citizenship (Cohen's $d=0.32$ ), and understanding community (Cohen's $d=0.21$ ). A negligible effect was observed in the area of managing conflict (Cohen's $d=0.09$ ). 
Table 3.

Comparing Mean Weighted Discrepancy Scores Before and After the Leadership Development Program

\begin{tabular}{|c|c|c|c|c|c|c|}
\hline \multirow[b]{2}{*}{ Leadership Area } & \multicolumn{2}{|c|}{$\mathrm{MWDS}^{1}$} & \multirow[b]{2}{*}{$\triangle \mathrm{MWDS}$} & \multirow[b]{2}{*}{$\begin{array}{c}t- \\
\text { value }\end{array}$} & \multirow[b]{2}{*}{$\begin{array}{c}p^{-} \\
\text {value }\end{array}$} & \multirow[b]{2}{*}{$\begin{array}{l}\text { Effect size } \\
\text { (Cohen's } d \text { ) }\end{array}$} \\
\hline & Pre Test & Post Test & & & & \\
\hline Awareness of Self & 5.14 & 3.67 & 1.47 & 1.60 & .117 & 0.47 \\
\hline Commitment to Serving & 7.36 & 5.25 & 2.11 & 1.89 & .066 & 0.56 \\
\hline Developing Teams & 5.27 & 3.66 & 1.61 & 1.77 & .084 & 0.52 \\
\hline Enhancing Communication & 6.22 & 4.25 & 1.97 & 3.26 & .002 & 0.96 \\
\hline Ethical Behavior & 4.85 & 2.90 & 1.95 & 2.72 & .009 & 0.80 \\
\hline Leading Change & 5.54 & 3.98 & 1.56 & 1.39 & .171 & 0.41 \\
\hline Managing Conflict & 6.11 & 5.76 & 0.35 & 0.32 & .752 & 0.09 \\
\hline Managing Projects & 5.88 & 4.20 & 1.68 & 1.97 & .055 & 0.58 \\
\hline Practicing Citizenship & 6.05 & 4.36 & 1.69 & 1.40 & .169 & 0.32 \\
\hline Sustaining Leadership & 5.61 & 3.88 & 1.73 & 1.48 & .147 & 0.43 \\
\hline Understanding Community & 6.15 & 5.34 & 0.81 & 0.70 & .485 & 0.21 \\
\hline Understanding Leadership & 5.54 & 3.28 & 2.26 & 2.91 & .006 & 0.86 \\
\hline Valuing Diversity & 5.20 & 3.43 & 1.77 & 1.66 & .103 & 0.49 \\
\hline
\end{tabular}

${ }^{1}$ Mean Weighted Discrepancy Score, higher score indicates a higher perceived need.

The final research question, "what experiences did students participate in, through the leadership development program, which focused on developing their specific leadership needs?" sought to provide information into the experiences faculty of this program unanimously identified as targeting the top five leadership skill areas developed over the course of the experience (see Table 4). These five leadership skill areas were identified based on the largest change in perceived leadership need before and after the leadership development experience and included understanding leadership $(\triangle \mathrm{MWDS}=2.26)$, commitment to serving ( $\triangle \mathrm{MWDS}=2.11$ ), enhancing communication ( $\triangle \mathrm{MWDS}=1.97)$, ethical behavior $(\triangle \mathrm{MWDS}=1.95)$, and valuing diversity $(\triangle \mathrm{MWDS}=1.77)$. 
Table 4.

Identifying Leadership Development Experiences Utilized to Develop the Top Five Leadership Skill Growth Areas

Leadership

Area $\quad$ Experiences ${ }^{1}$

Understanding Faculty members identified four seminars addressing understanding

Leadership leadership. These seminars included two panels of industry professionals discussing their personal leadership experiences, a 360 assessment of personal authenticity, and a peer reflection activity at the conclusion of the program. Additionally, reading and discussing the book How to Win Friends and Influence People, meeting with a faculty mentor for one to two hours per month, and involvement in an off-campus community organization were unanimously identified as experiences linked to increasing students' understanding of leadership.

Commitment to Faculty identified student participation in a giving back panel, in which Serving donors to the university shared their experiences as leaders at different phases of their lives as well as the importance of giving back, as building students' commitment to serving. Additionally, participation in an offcampus community organization was identified as a contributing factor to students' commitment to serving.

Enhancing Faculty members identified four seminars addressing enhanced Communication communication. These seminars included students practicing and providing feedback on clear and concise written messages, engaging in a first impression activity with peer feedback, developing and implementing meeting agendas, and a seminar focusing on identifying and working with difficult people. Additional experiences highlighted as building students' communication skills included working in peer advisory boards and structured faculty mentoring.

Ethical Faculty noted reading and discussing the book True North, the giving back Behavior panel, and being mentored by a faculty member as valuable experiences toward building ethical behavior.

Valuing Faculty identified reading and discussing the book True North as well as Diversity student participation in an off-campus community organization as building competence in valuing diversity.

${ }^{1}$ Only those experiences that all three faculty members unanimously identified as meeting the leadership area are described.

\section{Conclusions \& Recommendations}

With employers seeking employees with leadership skills (Day, 2001; McCall; 1998; Vicere \& Fulmer, 1998), the development of leadership among college students is an important consideration for all colleges and universities (Astin \& Astin, 2000). Colleges and universities have responded, with an increased focus on leadership development through a variety of 
experiences. Yet, a dearth of research exists exploring the links between leadership skill development and specific curricular experiences. Identification of curricular experiences that consistently relate to leadership development among college students has the potential to greatly increase the effectiveness of leadership education programs. This study identified leadership skill development among students enrolled in a year-long leadership development program using the leadership needs assessment (Velez et al., 2013). Additionally, this study provides potential links between leadership skill development and curricular experiences utilized in a year-long leadership development program.

Researchers calculated mean weighted discrepancy scores (MWDSs) for all participants at the beginning and end of a leadership development program. Researchers identified decreases in each of the 13 MWDSs from the beginning to the conclusion of the program, indicating leadership skills were developed. Due to the methods of this study, researchers cannot definitively attribute the change in leadership needs to participation in the leadership development program (i.e. we acknowledge development of leadership skills could be a product of maturity or experiences outside of the leadership development program). However, the evidence provided in this study suggests a relationship between involvement in the program and the development of leadership skills; thus, supporting the inputs, experiences, and outcomes model of student development (Astin, 1999). Future studies should consider the use of control groups, not involved in a leadership development program, when analyzing the leadership development of students as this may provide more concrete evidence of a relationship between leadership skill development and involvement in a leadership development program.

In addition to identifying the changes in leadership needs among students enrolled in this program, researchers sought to identify curricular experiences related to specific leadership skills. Researchers administered a survey to the three program faculty members, requesting their perception of the curricular experiences relating to each of the thirteen leadership skill areas. Those curricular experiences the faculty unanimously agreed on were included in the findings of this study. Additionally, only experiences related to the leadership skills areas with the highest change in leadership need area were discussed. The variety of curricular experiences utilized to develop these leadership skills represent pedagogical techniques corroborated by research, including experiential learning through community involvement (Allen \& Hartman, 2009; Day, 2001; Eich, 2008); mentoring (Allen \& Hartman, 2009; Day, 2001; Zimmerman-Oster \& Burkhardt, 2009); and reflection, specifically reflecting on community involvement experiences, personal development progress, and readings (Allen \& Hartman, 2009; Jenkins, 2012;

Zimmerman-Oster \& Burkhardt, 2009). Therefore, researchers recommend the consideration of these experiences when designing or offering leadership development experiences.

There is a need for definitive research linking curricular experiences to leadership skill development within leadership education literature. This study provided a unique protocol for exploring potential links between experiences and skill development. However, due to the limited population, the generalizability of these findings is limited. Therefore, future studies should consider the expansion of this methodology across leadership development programs to provide additional evidence of curricular experiences relating to leadership skill development among college students. 


\section{References}

Albert, J. F., \& Vadla, K. (2009). Authentic leadership development in the classroom: A narrative approach. Journal of Leadership Education, 8(1), 72-92. doi: $10.12806 / \mathrm{V} 8 / \mathrm{I} 1 / \mathrm{AB} 2$

Allen, S. J., \& Hartman, N. S. (2009). Sources of learning in student leadership development programming. Journal of Leadership Studies, 3(3), 6-16. doi: 10.1002/j1s.20119.

Andenoro, T., Allen, S., Haber-Curran, P., Jenkins, D., Sowick, M., Dugan, J., \& Osteen, L. (2013). National Leadership Education Research Agenda. Retrieved from http://leadershipeducators.org/Resources/Documents/NLEResearchAgenda.3.pdf

Association of Public and Land-Grant Universities [APLU]. (2009). Human Capacity Development The Road to Global Competitiveness and Leadership in Food, Agriculture, Natural Resources, and Related Sciences (FANRRS).Washington, DC. Retrieved from http://www.aplu.org/NetCommunity/ Document.Doc?id=1639

Astin, A. W. (1999). Student involvement: A developmental theory for higher education. Journal of College Student Development, 40(5), 518-529.

Astin, A. W., \& Astin, H. S. (2000). Leadership reconsidered: Engaging higher education in social change. Battle Creek, MI: W. K. Kellogg Foundation.

Blackwell, C., Cummins, R, Townsend, C. D., \& Cummings, S. (2007). Assessing perceived student leadership skill development in an academic leadership development program. Journal of Leadership Education, 6(1), 39-58. doi: 10.12806/V6/I1/RF1

Borich, G. D. (1980). A needs assessment model for conducting follow-up studies. Journal of Teacher Education, 31(3), 39-42. doi: 10.1177/002248718003100310

Brungardt, C., \& Crawford, C. B. (1996). A comprehensive approach to assessing leadership students and programs: Preliminary findings. Journal of Leadership Studies, 3(1), 37-48. doi: $10.1177 / 107179199600300105$

Cohen, J. (1988). Statistical power analysis for the behavioral sciences. Hillsdale, NJ: Erlbaum.

Conger, J. (1992). Learning to lead: The art of transforming managers into leaders. San Francisco, CA: Jossey-Bass.

Day, V. D. (2001). Leadership development: A review in context. Leadership Quarterly, 11(4), 581-613. doi: 10.1016/S1048-9843(00)0061-8

Eich, D. (2008). A grounded theory of high-quality leadership programs: Perspectives from student leadership programs in higher education. Journal of Leadership \& Organizational Studies, 15(2), 176-187. doi: 10.1177/1548051808324099 
Goertzen, B. J. (2009). Assessment in academic based leadership education programs. Journal of Leadership Education, 8(1), 148-162. doi: 10.12806/V8/I1/IB3

Jenkins, D. M. (2012). Exploring signature pedagogies in undergraduate leadership education. Journal of Leadership Education, 11(1), 1-27. doi: 10.12806/V11/I1/RF1

Kolb, D. A. (1984). Experiential learning: Experience as the source of learning and development. Englewood Cliffs, N.J.: Prentice-Hall.

McCall, M. W. (1998). High flyers: Developing the next generation of leaders. Boston, MA: Harvard Business School.

Morgan, A. C., King, D. L., Rudd, R. D., \& Kaufman, E. K. (2013). Elements of an undergraduate agricultural leadership program: A delphi study. Journal of Leadership Education, 12(1), 140-155. doi: 10.12806/V12/I1/140

National Association of Colleges and Employers [NACE]. (2014). The Skills and Qualities Employers Value Most in Their New Hires. Retrieved from http://www.naceweb.org/about-us/press/skills-employers-value-in-new-hires.aspx

Rosch, D. M., \& Caza, A. (2012). The durable effects of short-term programs on student leadership development. Journal of Leadership Education, 11(1), 28-48. doi: $10.12806 / \mathrm{V} 11 / \mathrm{I} 1 / \mathrm{RF} 2$

Rosch, D. M., \& Schwartz, L. M. (2009). Potential issues and pitfalls in outcomes assessment in leadership education. Journal of Leadership Education, 8(1), 177-194. doi: 10.12806/V8/I1/IB5

Velez, J. J., McKim, A. J., \& Simonsen, J. C. (2013). Importance versus competence: Identifying the needs of leadership students. Proceedings of the Association of Leadership Educators Annual Conference, 618-620, New Orleans, LA.

Vicere, A. A., \& Fulmer, R. M. (1998). Leadership by design. Boston, MA: Harvard Business School.

Williams, J. R., Townsend, C. D., \& Linder, J. R. (2005). Teaching leadership: Do students remember and utilize the concepts we teach? Journal of Leadership Education, 4(1), 62 74. doi: 10.12806/V4/I1/RF2

Zimmerman-Oster, K., \& Burkhardt, J. C. (1999). Leadership in the making: Impact and insights from leadership development programs in U.S. colleges and universities. Battle Creek, MI: W. K. Kellogg Foundation. 


\section{Author Biographies}

Aaron J. McKim is an Assistant Professor in the Department of Community Sustainability at Michigan State University. Aaron teaches courses in agriculture, food, and natural resources education, community sustainability, and leadership. Aaron's research interests include exploring educational approaches to develop the human potential to identify and implement sustainable solutions to ecological and social challenges. Email: amckim@msu.edu

Jonathan J. Velez, PhD, is an Associate Professor of Agricultural Education and Leadership at Oregon State University (OSU). Jonathan currently holds the Bradshaw Agricultural Sciences Leadership Education endowment and oversees the OSU Leadership Minor. Jonathan teaches both graduate and undergraduate leadership courses and his research interests include motivation, teaching methods, leadership development, and effective methods of leadership assessment. Email: jonathan.velez@oregonstate.edu 